\section{Nuclear damages and oxidative stress: new perspectives for laminopathies}

\author{
G. Lattanzi, ${ }^{1}$ S. Marmiroli, ${ }^{2}$ A. Facchini, ${ }^{3}$ \\ N.M. Maraldi ${ }^{4,5}$ \\ 'Institute of Molecular Genetics, C.N.R. \\ Unit of Bologna, c/o I.O.R., Bologna; \\ 2Department of Histology, University of \\ Modena and Reggio Emilia, Modena; \\ ${ }^{3}$ Laboratory of Immunorheumatology and \\ Tissue Regeneration, I.O.R., Bologna; \\ ${ }^{4}$ Laboratory of Musculoskeletal Cell \\ Biology, I.O.R., Bologna; \\ ${ }^{5}$ Department of Biomedical and \\ NeuroMotorial Sciences (Dibinem), \\ University of Bologna, Italy
}

\section{Abstract}

Mutations in genes encoding nuclear envelope proteins, particularly LMNA encoding the A-type lamins, cause a broad range of diverse diseases, referred to as laminopathies. The astonishing variety of diseased phenotypes suggests that different mechanisms could be involved in the pathogenesis of laminopathies. In this review we will focus mainly on two of these pathogenic mechanisms: the nuclear damages affecting the chromatin organization, and the oxidative stress causing un-repairable DNA damages. Alteration in the nuclear profile and in chromatin organization, which are particularly impressive in systemic laminopathies whose cells undergo premature senescence, are mainly due to accumulation of unprocessed prelamin A. The toxic effect of these molecular species, which interfere with chromatin-associated proteins, transcription factors, and signaling pathways, could be reduced by drugs which reduce their farnesylation and/or stability. In particular, inhibitors of farnesyl transferase (FTIs), have been proved to be active in rescuing the altered cellular phenotype, and statins, also in association with other drugs, have been included into pilot clinical trials. The identification of a mechanism that accounts for accumulation of unrepairable DNA damage due to reactive oxygen species (ROS) generation in laminopathic cells, similar to that found in other muscular dystrophies (MDs) caused by altered expression of extracellular matrix (ECM) components, suggests that anti-oxidant therapeutic strategies might prove beneficial to laminopathic patients.

\section{Laminopathies present a wide range of diseased phenotypes}

Mutations affecting the EMD gene that encodes the inner nuclear membrane-associated protein emerin cause the X-linked form of Emery-Dreifuss muscular dystrophy (EDMD1). ${ }^{1}$ An indistinguishable disease phenotype (EDMD2) is caused by mutations in the $L M N A$ gene encoding lamin $\mathrm{A} / \mathrm{C} .{ }^{2}$ The finding that the altered expression of two different proteins located at the nuclear envelope causes a similar diseased phenotype affecting the contractile tissues suggested the existence of a common pathogenic mechanism. ${ }^{3}$ Mutations in LMNA cause several tissue-specific diseases: the autosomal dominant form of EDMD ${ }^{2}$ the autosomal recessive form of $\mathrm{EDMD},{ }^{4}$ the limb-girdle muscular dystrophy type 1B (LGMD 1B), ${ }^{5}$ the dilated cardiomyopathy and conduction-system disease (CMDCD) ${ }^{6}$ the Dunningan-type familial partial lipodystrophy (FPLD2), ${ }^{7}$ and the Charcot-Marie Tooth disorder type 2 (CMT 2B1). ${ }^{8}$ Each disease selectively strikes one or more specific tissues, including skeletal and cardiac muscle, tendons, adipose tissue, and peripheral neurons.

A further group of laminopathies has been then identified, characterized by a systemic involvement of almost all the tissues, which undergo premature senescence. The progeric laminopathies include the Hutchinson-Gilford progeria, syndrome (HGPS) ${ }^{9,10}$ atypical progeroid syndrome, ${ }^{11}$ mandibuloacral dysplasia (MADA), ${ }^{12}$ and restrictive dermopathy (RD). ${ }^{13}$

Typical nuclear abnormalities consisting of altered nuclear envelope/lamina structure and focal loss of heterochromatin are observed in fibroblasts, myoblasts and muscle tissue from EDMD1 patients. ${ }^{14,15}$ Characteristic non-uniform distribution of both lamin $\mathrm{A} / \mathrm{C}$ and emerin have been reported in skin fibroblasts from EDMD2 patients. ${ }^{16,17}$ Ultrastructural alterations include nuclear lamina thickening, nuclear pore clustering, ${ }^{16}$ as well as focal absence of heterochromatin and loss of contact between heterochromatin and the nuclear lamina. ${ }^{16,18}$ No accumulation of abnormal prelamin A has been found in either biopsies or cultured cells from EDMD2 patients. ${ }^{19}$ Fibroblasts from FPLD2 patients present characteristic nuclear alterations, due to the accumulation of abnormal amounts of prelamin $A^{20,21}$ The dysmorphic FPLD2 nuclei present intranuclear prelamin A aggregates, an enlarged and irregular nuclear profile, and a reduced amount of peripheral heterochromatin. ${ }^{22}$

In dermal fibroblasts from HGPS, a-WS and MADA patients, typical nuclear alterations have been observed, mainly consisting in local
Correspondence: Dr. Nadir M. Maraldi, Laboratory of Musculoskeletal Cell Biology, I.O.R. via di Barbiano 1/10, 40136 Bologna, Italy. Tel. +39.051.6366856 - Fax: +39.051.583593. E-mail: maraldi@area.bo.cnr.it

Key words: laminopathies, nuclear envelope, chromatin, muscular dystrophies, progeria, oxidative stress, DNA damage.

Acknowledgements: this work was supported by grants from the A.I.Pro.Sa.B., Italy, the Italian MIUR PRIN 2008 to G.L. and FIRB to N.M.Maraldi, and by "5 per mille" 2010, I.0.R., Bologna, Italy.

Received for publication: 3 October 2012. Accepted for publication: 9 October 2012.

This work is licensed under a Creative Commons Attribution NonCommercial 3.0 License (CC BYNC 3.0).

(C) Copyright G. Lattanzi et al., 2012

Licensee PAGEPress, Italy

European Journal of Histochemistry 2012; 56:e45 doi:10.4081/ejh.2012.e45

or total loss of peripheral heterochromatin, associated with blebs and invaginations of the nuclear lamina. ${ }^{22-24}$ In HGPS cells, the worsening of chromatin alterations have been reported to increase with the age of the patient, as well as with the increasing amount of progerin. ${ }^{23,25,26}$ The cellular phenotype of RD, determined by accumulation of farnesylated prelamin A, causes severe nuclear envelope and chromatin abnormalities. ${ }^{27}$

\section{Pathogenic mechanisms}

The impressive variety of disease phenotypes of laminopathies rises the question of how mutation of a gene expressed in nearly every differentiated cell could give rise to many tissue-restricted pathologies. Besides their role in maintaining, in association with B-type lamins, the mechanical stability of the nuclear envelope (NE) throughout the phases of the cell cycle, A-type lamins and associated NE proteins represent scaffolds for molecular interaction with elements that regulate DNA synthesis and repair, higher-order chromatin organization, nuclear positioning, gene transcription, and cell differentiation. ${ }^{28,29}$ Many of these functions involve lamin A interplay with signal transduction pathways, transcription factors and chromatin-associated proteins. On this basis, different pathogenic mechanisms of laminopathies have been proposed which include: nuclear envelope defects affecting nuclear stiffness, ${ }^{29,30}$ nuclear envelope defects as determinants of altered nucleo-cytoplasmic 
interplay, ${ }^{31,32}$ altered cell cycle control, ${ }^{33}$ telomere dysfunction, ${ }^{34}$ altered cellular signalling, ${ }^{35,36}$ altered stem cell functioning. ${ }^{37,38}$

In the present review we will focus mainly on two further pathogenic mechanisms: i) alterations of the nuclear morphology affecting chromatin rearrangement; ii) altered DNA repair due to oxidative stress.

\section{Alterations of nuclear morphology affecting the chromatin arrangement}

Alterations of nuclear morphology are present in many types of laminopathies, frequently associated with alterations of the chromatin arrangement. Interestingly, distinct altered patterns of chromatin distribution characterize different classes of laminopathies. Severe nuclear abnormalities have been reported in HGPS, a-WS, RD and MADA cells, including lobulation, blebbing, and loss of heterochromatin. ${ }^{22,24-27,39}$ Aberrant nuclear morphology results in cellular senescence, down-regulation of transcription, and apoptosis. ${ }^{20,40}$ Furthermore, there is increasing evidence of a role for lamins in the regulation of epigenetic marks in chromatin. Loss of heterochromatin in HGPS and RD cells is associated with downregulation of trimethylation at Lys-9 of histone H3 (H3K9), and reduced association with heterochromatin protein $1 \alpha(H P 1 \alpha))^{23,27}$ Cells from older MADA patients also exhibit loss of peripheral heterochromatin, together with mislocalization of HP1 $\beta$, trimethylated H3K9, and $\mathrm{LBR}^{24}$ In all these cases, the nuclear defects appear to be not related to a loss of mature wild-type lamin A, but to a dominantnegative effect of aberrant prelamin A accumulation. ${ }^{41}$

In laminopathies affecting the muscle, nuclear alterations, that include nuclear lamina thickening, nuclear pore clustering, and focal detachment of peripheral heterochromatin, appear to be related to a loss of mature wild-type lamin A and to defective lamin phosphorylation. ${ }^{42,43}$ Alterations of the nuclear morphology occurring in muscular laminopathies also characterize sarcopenia, the age-related decline of muscle mass, strength and quality in elderly. It has been recently reported, by means of in situ immunocytochemistry, that the activity of pre-mRNA splicing and cleavage is impaired in the myonuclei of old muscles ${ }^{44}$ and that similar alterations are detectable in cultured myoblasts from DM2 patients, ${ }^{45}$ suggesting the possibility that these nuclear alterations might represent the basis of common pathogenic mechanisms in sarcopenia, myotonic dystrophy and laminopathies. ${ }^{46}$
Alterations in the nuclear arrangement have been reported in the tissues affected in different laminopathies and in cells cultured in vitro obtained from laminopathic patients or animal models of laminopathies. On the other hand, the specificity of nuclear alterations which characterize systemic laminopathies causing premature senescence with respect to those detected in muscular laminopathies, suggests that different mechanisms are involved in the pathogenesis of the two classes of laminopathies. In fact, the accumulation of farnesylated prelamin A occurring in systemic laminopathies results in defective interactions of the nuclear envelope with chromatin-associated proteins such as HP1, thus impairing the correct localization of heterochromatin domains at the nuclear periphery, and could have a repressive effect on gene transcription of chromosome domains or tissue-specific gene loci. $^{47,48}$ In muscular laminopathies, nuclear alterations are less evident ${ }^{49}$ and mainly detectable with immunocytochemical methods, such as defects related to defective lamin A phosphorylation, ${ }^{42}$ altered pRb-mediated activation of cellular differentiation, ${ }^{50}$ excess accumulation of phosphorylated Smad2 and Smad3 in nuclei..$^{51}$ It is also conceivable that, as it has been reported in sarcopenia and myotonic dystrophy ${ }^{46}$ pre-mRNA splicing and cleavage is impaired in muscular laminopathies.

\section{Altered DNA repair due to oxidative stress}

Oxidative stress refers to a cell state where the production of reactive oxygen species (ROS), mainly produced by mitochondria and NADPH oxidases, is higher than its removal. In response to oxidative stress, the gene expression is modulated in order to activate various redox-transcription factors, such as $\mathrm{Rb}, \mathrm{p} 53$, NF-kB and Fox0; $; 2$ however, whilst oxidants in the cytoplasm are able to activate this redox signalling, oxidative stress in the nucleus blocks this process. ${ }^{53}$

Recent evidence points to a relationship between lamin mutation and altered ROS metabolism..$^{54}$ Accumulation of fanesylated prelamin A in progeric laminopathies induces excessive ROS and reduces the level of antioxidant enzymes. ${ }^{55-57}$ Apart from a direct damaging effect to coding sequences, ROS can affect the lamin structure, thus promoting cellular senescence and susceptibility to ROS. ${ }^{55}$ Downstream effects of ROS include persistent DNA damage, ${ }^{58}$ and telomere shortening, ${ }^{59}$ mechanisms that have been suggested to be involved into the pathogenesis of laminopathies. ROS accumulate at a higher rate in HGPS fibroblasts, as well as in normal- ly aged fibroblasts; ${ }^{56}$ this may contribute to increased levels of DNA damage and may trigger senescence in HGPS cells. ${ }^{60}$ Moreover, oxidative stress appears involved in the pathogenesis of FPLD, whose fibroblasts undergo p16-dependent senescent arrest. ${ }^{21}$ Impaired DNA repair, and genomic instability also characterize MEFs of Zmpste24-null mice, as well as bone marrow cells and HGPS or RD fibroblasts undergoing premature senescence. ${ }^{61}$ Fibroblasts from HGPS and MADA patients show increased amounts of basal phosphorylated histone variant $\mathrm{H} 2 \mathrm{AX}(\gamma \mathrm{H} 2 \mathrm{AX})$, a marker of DNA damage sites. ${ }^{62,63}$ Gamma-H2AX colocalizes with XPA foci, an essential factor of nucleotide excision repair (NER) and not with double-strand breaks (DBSs), suggesting that the damage in HGPS cells may be different from that accrued by other genotoxic agents. ${ }^{62}$ Furthermore, fibroblasts from HGPS patients show a marked delay in the recruitment of p53 binding protein 1 (53BP1) to sites of DNA repair. $^{61}$

A dysfunctional lamina may influence ROS in several ways, because the lamina serves a a docking site for transcription factors and chromatin-associated proteins. ${ }^{35}$ In HGPS fibroblasts and in ZMPSTE24^ MEFs the recruitment of the repair factor p53-binding protein (53BP1) to sites of DNA damage is impaired, as well as the presence of fragmented DNA after irradiation. ${ }^{61}$ Expression of HGPS mutant lamin A in HeLa cells increases the levels of phosphorylated histone H2AX ( $\gamma$-H2AX), a hallmark of double strand breaks, and this is correlated with defects in DNA repair foci. ${ }^{64}$ Other DNA damage signalling pathways, including ATM and ATR kinases as well as Rad50 and Rad51, are affected in HGPS and RD fibroblasts. ${ }^{65}$ These findings suggest that defects in the DNA repair machinery are due to expression of abnormal levels of farnesylated prelamin A in progeric laminopathies.

DNA damage-initiated genomic instability as well as p53-mediated cell senescence and apoptosis in response to DNA damage may contribute to aging. ${ }^{66}$ In a recent study, it has been demonstrated that whilst the DNA damage induced by etoposide could be repaired in progeroid fibroblasts, many of double strand breaks (DSB) induced by ROS are unrepairable. Moreover, because the treatment with a ROS scavenger can reduce the amount of DSB, it has been suggested that the accumulation of un-repairable DNA damages could be mainly due to the ROS-generating environment present in progeroid fibroblasts. ${ }^{67}$

As far as the mechanism leading to DBS in laminopathic cells is concerned, it has been hypothesized that, in normal condition, the nuclear lamina could represent a nuclear shield against ROS, being a preferential docking site for ROS defusing enzymes, such as 
CAT, GPX and GST, whose concentration in the nucleus are several fold higher than in the cytosol. ${ }^{68}$ In the presence of mutant lamin A, the formation of the nuclear shield could be affected, resulting in a higher susceptibility to oxidative stress.

A general relationship between ROS, mitochondrial dysfunction, and the pathophysiology of muscular dystrophies (MDs) has been widely reported..$^{69,70}$ This relationship has been further supported by genetic ${ }^{71}$ or pharmacological reduction of the open probability of the PTP which prevent myofiber injury in animal models of MDs, ${ }^{72}$ as well as in patients with collagen VI myopathies. ${ }^{73}$ In laminopathies, accumulation of farnesylated prelamina A also affects the expression of the mtDNA encoded subunit II of the cytochrome oxidase comple IV (COX 2), lowering the mitochondrial potential and generating ROS; ${ }^{21}$ moreover, accumulation of farnesylated prelamin A in Zmpste24-- mice also causes an increased mitochondrial response to oxidative stress, further supporting a relationship between defective lamin A processing and mitochondrial dysfunction. ${ }^{74}$

A relevant source of ROS in mitochondria is represented by MAOs, located in the outer mitochondrial membrane, that catalyze the oxidative deamination of neurotransmitters and dietary amines, generating hydrogen peroxide. MAO have been studied at the level of nervous system, ${ }^{75}$ leukemic cells, ${ }^{76}$ and in cardiac diseases. ${ }^{77}$ In skeletal muscle it has been recently reported that ROS related to MAO activity plays a pivotal role in loss of cell viability and contractile derangements in different animal models of MDs, causing oxidation of myfibrillar proteins. ${ }^{78}$

\section{Molecular targets for a pharmacological treatment of laminopathies}

Farnesylated lamin A exerts a dominant effect on the pathophysiology of HGPS ${ }^{25}$ and MAD ${ }^{24}$ farnesyl transferase inhibitors (FTIs) can block prelamin A processing and reduce the percentage of cells with misshapen nuclei ${ }^{79}$ and recover nuclear transcription activity. ${ }^{23,41}$

Signaling pathway required to maintain normal stem cell function have been reported to be perturbed in cells expressing high levels of unprocessed prelamin A. In particular, expression of progerin activates down-stream effectors of the Notch signalling pathway and alters the differentiation potential of stem cells. $^{80}$ Alterations of signalling pathways involved in regulation of stem cells, such as Wnt, have been reported in Zmpste24 null mice. ${ }^{81}$ FTI treatment of HGPS cells did not result in a reduction in DNA double strand breaks and damage checkpoint signalling, suggesting that DNA damage accumulation and aberrant nuclear morphology are independent phenotypes due to accumulation of progerin. ${ }^{65}$ Ideally, the therapy of progeroid syndromes needs to achieve both restoration of nuclear morphology and transcriptional ability, as well as improvement of DNA damage repair mechanisms. Amino-bisphosphonates (N-BPs), that are used to prevent osteoporosis and the risk of pathological fractures in bone malignancies, act as inhibitors of farnesyl-phyrophosphate synthase, thus reducing the synthesis of both geranyl-geranyl and farnesyl groups. Their use, in combination with statins, reduces nuclear defects and partly rescues the disease phenotype in Zmpste24 null mice. ${ }^{82}$ Pharmacological inhibitors of ERK1/2, whose hyperactivation has been related to the pathogenesis of DCM in EDMD ${ }^{83}$ have been found to block the development of cardiomyopathy in Lmna ${ }^{\text {H222PHI222P }}$ mice, before the appearance of clinical symptoms. ${ }^{84}$ We have recently reported that activation of the m-TOR-dependent autophagic pathway using rapamycin can counteract progerin accumulation in HGPS cells, leading to the rescue of the chromatin phenotype of senescent cells. ${ }^{85}$ The availability of a drug capable of triggering degradation of farnesylated prelamin A paves the way to the treatment of other laminopathies featuring accumulation of farnesylated prelamin forms different from progerin. The treatment of progeroid fibroblasts with the ROS scavenger $\mathrm{N}$-acetyl cysteine (NAC) has been demonstrated to reduce the levels of un-repairable DSB and to improve their growth rate in culture. Because the ROS-generating environment is the primary cause of the accumulation of unrepairable DNA damage, the use of ROS scavengers in conjunction with FTIs might improve quality of life for progeric laminopathic patients. ${ }^{67}$

The recent demonstration that pargyline, an MAO inhibitor, is able to reduce ROS accumulation and exerts a beneficial effect on the dystrophic phenotype in mice models of collagen VI and Duchenne myopathies, adds evidence of the pivotal role of mitochondrial dysfunction in different muscular dystrophies ${ }^{78}$ and suggest a therapeutic potential for MAO inhibitors also in laminopathies. Determining the molecular mechanisms by which the loss of A-lamins impacts on the different pathways regulating chromatin rearrangements, and DNA repair in the presence of increased ROS production, will be fundamental not only for understanding the pathogenic mechanisms but also for the development of further therapeutic strategies to treat these diseases.

\section{References}

1. Bione S, Maestrini E, Rivella S, Mancini M, Regis S, Romeo G, et al. Identification of a novel X- linked gene responsible for EmeryDreifuss muscular dystrophy. Nat Genet 1994;8:323-7.

2. Bonne G, Di Barletta MR, Varnous S, Becane HM, Hammouda EH, Merlini L, et al. Mutations in the gene encoding lamin A/C cause autosomal dominant Emery-Dreifuss muscular dystrophy. Nat Genet 1999;21:2858.

3. Maraldi NM, Merlini L. Emery-Dreifuss muscular dystrophy. In: Myology, AG Engel, C Franzini-Armstrong (eds.). New York: McGraw-Hill, 2004, pp. 1027-38.

4. Raffaele Di Barletta M, Ricci E, Galluzzi G, Tonali P, Mora M, Morandi L, et al. Different mutations in the LMNA gene cause autosomal dominant and autosomal recessive Emery-Dreifuss muscular dystrophy. Am J Hum Genet 2000;66:1407-12.

5. Muchir A, Bonne G, Van Der Kooi AJ, van Meegen M, Baas F, Bolhuis PA, et al. Identification of mutations in the gene encoding lamins $\mathrm{A} / \mathrm{C}$ in autosomal dominant limb girdle muscular dystrophy with atrioventricular conduction disturbances (LGMD1B). Hum Mol Genet 2000;9:1453-9.

6. Fatkin D, MacRae C, Sasaki T, Wolff MR, Porcu M, Frenneaux M, et al. Missense mutations in the rod domain of the lamin $\mathrm{A} / \mathrm{C}$ gene as causes of dilated cardiomyopathy and conduction-system disease. N Engl J Med 1999;341:1715-24.

7. Shackleton S, Lloyd DJ, Jackson SN, Evans R, Niermeijer MF, Singh BM, et al. LMNA encoding lamin $\mathrm{A} / \mathrm{C}$ is modulated in partial lipodystrophy. Nat Genet 2000;24:153-6.

8. De Sandre-Giovannoli A, Chaouch M, Kozlov S, Vallat JM, Tazir M, Kassouri N, et al. Homozygous defects in LMNA, encoding lamin $\mathrm{A} / \mathrm{C}$ nuclear-envelope proteins, cause autosomal recessive axonal neuropathy in human (Charcot-Marie-Tooth disorder type 2) and mouse. Am J Human Genet 2002;70:726-36.

9. De Sandre-Giovannoli A, Bernard R, Cau P, Navarro C, Amiel J, Boccaccio I, et al. Lamin A truncation in Hutchinson-Gilford progeria. Science 2003;300:2055.

10. Eriksson M, Brown WT, Gordon LB, Glynn MW, Singer J, Scott L, et al. Recurrent de novo point mutations in lamin A cause Hutchinson-Gilford progeria syndrome. Nature 2003;423:293-8.

11. Garg A, Subramayam L, Agarwal AK, Simha V, Levine B, D'Apice MR, et al. Atypical progeroid syndrome due to heterozygous missense LMNA mutations. J Clin Endocrinol Metab 2009;94:4971-83. 
12. Novelli G, Muchir A, Sangiuolo F, HelbingLeclerc A, D'Apice MR, Massart C, et al. Mandibuloacral dysplasia is caused by a mutation in LMNA-encoding lamin A/C. Am J Hum Genet 2002,71:426-31.

13. Navarro CL, De Sandre-Giovannoli A, Bernard R, Boccaccio I, Boyer A, Genevieve D. et al. Lamin A and ZMPSTE24 (FACE-1) defects cause nuclear disorganization and identify restrictive dermopathy as a lethal neonatal laminopathy. Hum Mol Genet 2004;13:2493-2503.

14. Ognibene A, Sabatelli P, Petrini S, Squarzoni S, Riccio M, Santi S, et al. Nuclear changes in a case of $\mathrm{X}$-linked Emery-Dreifuss muscular dystrophy. Muscle Nerve 1999;22:864-9.

15. Maraldi NM, Lattanzi G, Sabatelli P, Ognibene A, Squarzoni S. Functional domains of the nucleus: implications for Emery-Dreifuss muscular dystrophy. Neuromuscul Disord 2002;12:815-23.

16. Sabatelli P, Lattanzi G, Ognibene A, Columbaro M, Capanni C, Merlini L, et al. Nuclear alterations in autosomal-dominant Emery-Dreifuss muscular dystrophy. Muscle Nerve 2001;24:826-9.

17. Maraldi NM, Lattanzi G, Capanni C, Columbaro M, Mattioli E, Sabatelli P, et al. Laminopathies: a chromatin affair. Adv Enzym Regul 2006;46:33-49.

18. Maraldi NM, Lattanzi G, Squarzoni S, Sabatelli P, Marmiroli S, Ognibene A, Manzoli FA. At the nucleus of the problem: nuclear proteins and disease. Advan Enzym Regul 2003;43:411-43.

19. Maraldi NM, Lattanzi G, Capanni C, Columbaro M, Merlini L, Mattioli E, et al. Nuclear envelope proteins and chromatin arrangement: a pathogenic mechanism for laminopathies. Eur J Histochem 2006; 50:1 8.

20. Capanni C, Cenni V, Mattioli E, Sabatelli P, Ognibene A, Columbaro M, et al. Failure of lamin $\mathrm{A} / \mathrm{C}$ to functionally assemble in R482L mutated familial partial lipodystrophy fibroblasts: altered intermolecular interaction with emerin and implications for gene transcription. Exp Cell Res 2003;291:122-34.

21. Caron M, Auclair M, Donadille B, Bereziat V, Guerci B, Laville M, et al. Human lipodystrophies linked to mutations in A-type and to HIV protease inhibitor therapy are both associated with prelamin A accumulation, oxidative stress and premature cellular senescence. Cell Death Differ 2007;14:175967.

22. Capanni C, Mattioli E, Columbaro M, Lucarelli E, Parnaik VK, Novelli G, et al. Altered prelamin A processing is a common mechanism leading to lipodystrophy. Hum Mol Genet 2005;14:1489-502.

23. Columbaro M, Capanni C, Mattioli E, Novelli
G, Parnaik VK, Squarzoni S, et al. Rescue of heterochromatin organization in Hutchinson-Gilford progeria by drug treatment. Cell Mol Life Sci 2005;62:2669-78.

24. Filesi I, Gullotta F, Lattanzi G, D’Apice MR, Capanni C, Nardone AM, et al. Alterations of the nuclear envelope and chromatin organization in mandibuloacral dysplasia, a rare form of laminopathy. Physiol Genomics 2005;23:150-8.

25. Goldman RD, Shumaker DK, Erdos MR, Eriksson M, Goldman AE, Gordon LB, et al. Accumulation of mutant lamin A causes progressive changes in nuclear architecture in Hutchinson-Gilford progeria syndrome. Proc Natl Acad Sci USA 2004;101:8963-8.

26. Shumaker DK, Dechat T, Kohlmaier A, Adam SA, Bozovsky MR, Erdos MR, et al. Mutant nuclear lamin A leads to progressive alterations of epigenetic control in premature aging. Proc Natl Acad Sci USA 2006;103:8703-8

27. Columbaro M, Mattioli E, Schena E Capanni C, Cenni V, Levy N, et al. Prelamin A processing and functional effects in restrictive dermopathy. Cell Cycle 2010; 9:4766-8.

28. Maraldi NM, Squarzoni S, Sabatelli P, Capanni C, Mattioli E, Ognibene A, et al., Laminopathies: involvement of structural nuclear proteins in the pathogenesis 0 fan increasing number of human diseases. $\mathrm{J}$ Cell Physiol 2005;203:319-27.

29. Maraldi NM, Mazzotti G, Rana R, Antonucci A, Di Primio R, Guidotti L. The nuclear envelope, human genetic diseases and ageing. Eur J Histochem 2007;51(Suppl.1):117-24.

30. Lammerding J, Schulze PC, Takahashi T, Kozlov S, Sullivan T, Kamm RD, et al. Lamin $\mathrm{A} / \mathrm{C}$ deficiency causes defective nuclear mechanics and mechanotransduction. J Clin Invest 2004;113:370-8.

31. Wheeler MA, Davies JD, Zhang Q, Emerson LJ, Hunt J, Shanahan CM, et al. Distinct functional domains in nesprin-1 alpha and nesprin- 2 beta bind directly to emerin and both interactions are disrupted in X-linked Emery-Dreifuss muscular dystrophy. Exp Cell Res 2007;313:2845-57.

32. Mattioli E, Columbaro M, Capanni C, Maraldi NM, Cenni V, Scotlandi K, et al. Prelamin A-mediated recruitment of SUN1 to the nuclear envelope directs nuclear positioning in human muscle. Cell Death Differ 2011;18:1305-15.

33. Naetar N, Foisner R. Lamin complexes in the nuclear interior control progenitor cell proliferation and tissue homeostasis. Cell Cycle 2009;8:1488-93.

34. Raz V, Vermolen BJ, Garini Y, Omderwater JJ, Mommaas-Kienhuis MA, Koster AJ, et al. The nuclear lamina promotes telomere aggregation and centromere peripheral localization during senescence of human mesenchymal stem cells. J Cell Sci 2008; 121:4018-28.

35. Heessen S, Fornerod M. The inner nuclear envelope as a transcription factor resting place. EMB0 Rep 2007;8:914-9.

36. Maraldi NM, Capanni C, Cenni V, Fini M, Lattanzi G. Laminopathies and lamin-associated signaling pathways. J Cell Biochem 2011;112:979-82.

37. Dechat T, Pfleghaar K, Sengupta K, Shimi T, Shumaker DK, Solimando, L et al. Nuclear lamins: major factors in the structural organization and function of the nucleus and chromatin. Genes Dev 2008;22:832-53.

38. Pekovic V, Hutchison CJ. Adult stem cell maintenance and tissue regeneration in the ageing context: the role for A-type lamins as intrinsic modulators of ageing in adult stem cells and their niches. J Anat 2008;213:5-25.

39. Muchir A, van Engelen BG, Lammens M, Mislow JM, McNally E, Schwartz K, et al. Nuclear envelope alterations in fibroblasts from LGMD1B patients carrying nonsense Y259X heterozygous or homozygous mutation in lamin $\mathrm{A} / \mathrm{C}$ gene. Exp Cell Res 2004;291:352-62

40. Lammerding J, Hsiao J, Schulze PC, Kozlov S, Stewart CL, Lee RT. Abnormal nuclear shape and impaired mechanotransduction in emerin-deficient cells. J Cell Biol 2006 170:781-91.

41. Maraldi NM, Lattanzi G. Involvement of prelamin A in laminopathies. Crit Rev Eukaryot Gene Expr 2007;17:317-34.

42. Cenni V, Sabatelli P, Mattioli E, Marmiroli S, Capanni C, Ognibene A, et al. Lamin A N terminal phosphorylation is associated with myoblast activation: impairment in EmeryDreifuss muscular dystrophy. J Med Genet 2005;42:214-20.

43. Cenni V, Bertacchini J, Beretti F, Lattanzi G, Bavelloni A, Riccio M, et al. Lamin A Ser404 is a nuclear target of Akt phosphorylation in C2C12 cells. J Proteome Res 2008;7:4727 35.

44. Malatesta M, Perdoni F, Muller S, Zancanaro C, Pellicciari C. Nuclei of aged myofibres undergo structural and functional changes suggesting impairment in RNA processing. Eur J Histochem 2009;53:e12.

45. Malatesta M, Giagnacovo M, Renna LV, Cardani R, Meola G, Pellicciari C. Cultured myoblasts from patients affected by myotonic dystrophy type 2 exhibit senescence-related features: ultrastructural evidence. Eur J Histochem 2011:55:e26.

46. Malatesta M, Meola G. Structural and functional alterations of the cell nucleus in skeletal muscle wasting: the evidence in situ. Eur J Histochem 2010:54:e44.

47. Maraldi NM, Lattanzi G. Linkage of lamins to fidelity of gene transcription. Crit Rev 
Eukaryot Gene Exp 2005;15:277-293.

48. Benson EK, Lee SW, Aaronson SW. Role of progerin-induced telomere dysfunction in HGPS premature cellular senescence. J Cell Sci 2010;123:2605-12.

49. Maraldi NM, Capanni C, Del Coco R, Squarzoni S, Columbaro M, Mattioli E, et al. Muscular laminopathies: role of prelamin A in early steps of muscle differentiation. Advan Enzym Regul 2011;51:246-56.

50. Markiewicz E, Ledran M, Hutchinson CJ. Remodelling of the nuclear lamina and nucleoskeleton is required for skeletal muscle differentiation in vitro. $\mathrm{J}$ Cell Sci 2005;118:409-20.

51. Arimura T, Helbling-Leclerc A, Massart C, Varnou S, Niel F, Lacene E, et al. Mouse model carryng H222P Lmna mutation develops muscular dystrophy and dilated cardiomyopathy similar to human striated muscle laminopathies. Hum Mol Genet 2005;14:155-69.

52. Allen RG, Tresini M. Oxidative stress and gene regulation. Free Rad Bio Med 2000; 28:463-9.

53. Hansen JM, Go YM, Jones DP. Nuclear and mitochondrial compartmentation of oxidative stress and redox signaling. Annu Rev Pharmacol Toxicol 2006;46:215-34.

54. Sieprath T, Darwiche R, De Vos WH. Lamins as mediators of oxidative stress. Biochem Biophys Res Com 2012;421:635-9.

55. Pekovic V, Gibbs-Seymour I, Markiewicz E, Alzoghaibi F, Benham AM, Edwards R, et al. Conserved cysteine residues in the mammalian lamin A tail are essential for cellular responses to ROS generation. Aging Cell 2011;10:1067-79.

56. Viteri G, Chung YW, Stadman ER. Effect of progerin on the accumulation of oxidized proteins in fibroblasts from HutchinsonGilford progeria patients. Mech Ageing Dev 2010;131:2-8.

57. De Vos WH, Houben F, Kamps M, Malhas A, Verheyen F, Cox J, et al. Repetitive disruptions of the nuclear envelope invoke temporary loss of cellular compartmentalization in laminopathies. Hum Mol Genet 2011;20: 4175-86.

58. Hutchison CJ. The role of DNA damage in laminopathy progeroid syndromes. Biochem Soc Trans 2011;39:1715-8.

59. Richter T, von Zglinicki T. A continuous correlation between oxidative stress and telomere shortening in fibroblasts. Exp Geront 2007;42:1039-42.

60. Gonzales-Suarez I, Redwood AB, Perkins SM, Vermolen B, Lichtensztejin D, Grotsky DA, et al. Novel roles for A-type lamins in telomere biology and the DNA damage response pathway. EMBO J 2009;28:241427.

61. Liu BH, Wang JM, Chan KM, Tjia WM, Deng W, Guan XY, et al. Genomic instability in laminopathy-based premature aging. Nat Med 2005;11:780-5.

62. Liu YY, Wang Y, Rusinol, Sinensky MS, Liu J, Shell SM, Zou Y. Involvement of xeroderma pigmentosum group A (XPA) in progeria arising from defective maturation of prelamin A: FASEB J 2008;22:603-11.

63. di Masi A, D'Apice MR, Ricordy R, Tanzarella C, Novelli G. The R527H mutation in LMNA gene causes an increase sensitivity to ionizing radiation. Cell Cycle 2008;7:2030-7.

64. Manjuou K, Muralikrishna B, Parnaik VK. Expression of disease-causing lamin A mutants impairs the formation of DNA repair foci. J Cell Sci 2006;119:2704-14.

65. Liu YY, Rusinol A, Sinensky M, Wang YJ, Zou Y. DNA damage responses in progeroid syndromes arise from defective maturation of prelamin A. J Cell Sci 2006;119:4644-9.

66. Vousden KH, Lane DP. P53 in health and disease. Nat Rev Mol Cell Biol 2009;8:275-83.

67. Richards SA, Muter J, Ritchie P, Lattanzi G, Hitchison CJ. The accumulation of unrepairable DNA damage in laminopathy progeria fibroblasts is caused by ROS generation and is prevented by treatment with $\mathrm{N}$ acetyl cysteine. Hum Mol Genet 2011; 20:3997-4004.

68. Fabrini R, Bocedi A, Pallottini V, Canuti L, De Canio M, Urbani A, et al. Nuclear shield: a multi-enzyme task-force for nuclear protection. PLOS ONE 2010;5:1-11.

69. genesis of muscular dystrophies. Am J Phys Med Rehabil 2002;81:S175-S186.

70. Tidball JG, Wehling-Hendicks M. The role of free radicals in the pathophysiology of muscular dystrophy. J Appl Physiol 2007;102: 1677-86.

71. Palma E, Tiepolo T, Angelin A, Sabatelli P, Maraldi NM, Basso E, et al. Genetic ablation of cyclophilin D rescues mitochondrial defects and prevents muscle apoptosis in collagen VI myopathic mice. Hum Mol Genet 2009;18:2024-31.

72. Tiepolo T, Angelin A, Palma E, Sabatelli P, Merlin L, Nicolosi L, et al. The cyclophilin inhibitor Debio 025 normalizes mitochondrial function, muscle apoptosis and ultrastructural defects in Col6al(-/-) myopathic mice. Br J Pharmacol 2009;157:1045-52.

73. Merlini L, Angelin A, Tiepolo T, Braghetta P, Sabatelli P, Zamparelli A, et al. Cyclosporin A corrects mitochondrial dysfunction and muscle apoptosis in patients with collagen VI myopathies. Proc Natl Acad Sci USA 2008;105:5225-9.

74. Peinado JR, Quiros PM, Pilido MR, Marino G, Martinez-Chantar ML, Vasquez-Martinez $\mathrm{R}$, et al., Proteomic profiling of adipose tissue from Zmpste24(-/) mice, a model of lipodystrophy and premature aging, reveals major changes in mitochondrial function and vimentin processing. Mol Cell Proteomics 2011;10:1-16.
75. Maraldi T, Prata C, Caliceti C, Vieceli Dalla Sega F, Zambonin L, Fiorentini D, Hakim G. VEGF-induced ROS generation from $\mathrm{NAD}(\mathrm{P}) \mathrm{H}$ oxidases protects human leukemic cells from apoptosis. Int $\mathrm{J}$ Oncology 2010;36:1581-9.

76. Maraldi T, Riccio M, Zambonin L, Vinceti M, De Pol A, Hakim G. Low levels of selenium compounds are selectively toxic for a human neuron cell line through ROS/RNS increase and apoptotic process activation. Neurotoxicology 2011;32:180-7.

77. Bianchi P, Kunduzova 0, Masini E, Cambon C, Bani D, Raimondi L, et al. Oxidative stress by monoamine oxidase mediates receptor-independent cardiomyocyte apoptosis by serotonin and post-ischemic myocardial injury. Circulation 2005;112: 3297-305.

78. Menazza S, Blaauw B, Tiepolo T, Toniolo L, Braghetta P, Spolaore B, et al. Oxidative stress by monoamine oxidases is causally involved in myofiber damage in muscular dystrophy. Hum Mol Genet 2010;19:4207-15.

79. Glynn MW, Glover TW. Incomplete processing of mutant lamin A in Hutchinson-Gilford progeria leads to nuclear abnormalities, which are reversed by farnesyltransferase inhibition. Hum Mol Genet 2005;14:2959-69.

80. Scaffidi P, Misteli T. Lamin A-dependent misregulation of adult stem cells associated with accelerated ageing. Nat Cell Biol 2008;10:452-9.

81. Espada J, Varela I, Flores I, Ugalde AP, Cadinanos J, Pendas AM, et al. Nuclear envelope defects cause stem cell dysfunction in premature-aging mice. $\mathrm{J}$ Cell Biol 2008;181:27-35.

82. Varela I, Pereira S, Ugalde AP, Navarro CL, Suarez MF, Cau P et al. Combined treatment with statins and aminobisphosphonates extends longevity in a mouse model of human premature aging. Nat Med 2008; 14:767.72.

83. Muchir A, Pavlidis P, Bonne G, Hayashi YK, Worman HJ. Activation of MAPK in hearts of Emd null mice: similarities between mouse models of X-linked and autosomal dominant Emery-Dreifuss muscular dystrophy. Hum Mol Genet 2007;16:1884-95.

84. Muchir A, Shan J, Bonne G, Lehnart SE, Worman HJ. Inhibition of extracellular signal-regulated kinase signaling to prevent cardiomyopathy caused by mutation in the gene encoding A-type lamins. Hum Mol Genet 2009;18:241-7.

85. Cenni V, Capanni C, Columbaro M, Ortolani M, D’Apice MR, Novelli G, et al. Autophagic degradation of farnesylated prelamin $\mathrm{A}$ as a therapeutic approach to lamin-linked progeria. Eur J Histochem 2011;55:e36. 